\title{
FATORES DO AMBIENTE DE HOTÉIS E A EXPERIÊNCIA DE CONSUMO: UMA PESQUISA QUALITATIVA COM HOMOSSEXUAIS DO RECIFE
}

\author{
Juliana Pinheiro da Silva \\ Bacharel em Hotelaria na Universidade Federal de Pernambuco - UFPE \\ E-mail: julianapds@hotmail.com (Brasil)
}

\section{Yákara Vasconcelos Pereira Leite}

Doutoranda pelo PPGA da Universidade Federal de Pernambuco - UFPE

Docente da Universidade Federal Rural do Semi-Árido - UFERSA

E-mail: yakarav@gmail.com (Brasil)

\section{RESUMO}

Este estudo tem o objetivo de descrever os fatores do ambiente de hotéis que mais influenciam a experiência de consumo dos homossexuais entrevistados em Recife. Buscando descobrir as perspectivas dos respondentes do gênero masculino residentes na cidade do Recife, desenvolveu-se uma pesquisa qualitativa com entrevista semi estruturada. Os resultados indicaram que a iluminação, a limpeza e o aroma (condições ambientais); a cama, a área de preferência e a funcionalidade (espaço e funcionalidade); a decoração (sinais, símbolos e artefatos); o café da manhã e a TV a cabo (benefícios extrínsecos); e os funcionários dos hotéis (fator social do ambiente de hotéis) são os elementos que mais influenciaram a experiência de consumo dos homossexuais entrevistados.

Palavras-chave: Ambiente de Serviços; Experiência do Consumidor; Hotel.

REMark - Revista Brasileira de Marketing, São Paulo, v. 8, n. 1, p 43-69, jan./jun. 2009. 


\section{INTRODUÇÃO}

A compreensão do comportamento do consumidor e a influência no consumo parecem ser os maiores desafios dos cientistas e profissionais de marketing. Diante da competição globalizada, o cliente torna-se um organismo de análise para que se possa atingir a sua fidelidade. Considerandose os diferentes segmentos de mercado, o público gay (homossexuais do sexo masculino e feminino em inglês) vem, nos últimos anos, ganhando espaço. GLS é a sigla para gays, lésbicas e simpatizantes (FISCHER, 2006).

As pesquisas sobre esse público ainda são incipientes. Uma subcultura de consumo (KATES, 1998, 2002; NUNAN, 2003; PEÑAZOLA, 1996; PEREIRA; AYROSA; OJIMA, 2005) que tem sido pouco explorada por estudiosos e empresários e que apresenta grandes oportunidades de lucro é o público homossexual. Entretanto, alguns pesquisadores já perceberam o seu valor. Os gays e lésbicas foram considerados um segmento dos sonhos por Wardlow (1996, p. 1) pelo fato de sua renda ser avaliada como maior que a da média da população e ao seu significativo desejo em consumir.

O mercado de gays do gênero masculino e de lésbicas no País é constituído por $10 \%$ da população brasileira, o que significa mais de 18 milhões de consumidores em busca de produtos e serviços personalizados, e gastam cerca de $30 \%$ a mais do que os consumidores heterossexuais. A Parada Gay em São Paulo em 2006 ofereceu uma pequena amostra da atratividade desse mercado. A Parada atraiu turistas de outras cidades, estados e, até mesmo do exterior, que chegavam com antecedência ao evento e gastaram no comércio local entre 180 e 200 milhões de reais, não contabilizando os gastos com transporte e hospedagem, semelhante ao que aconteceu em 2009. Isso e outros motivos, que serão tratados com mais profundidade ao decorrer da pesquisa, explicam o fato de cada vez mais haver investimentos por parte das empresas no segmento. Percebendo a força desse mercado, o canal ForMan da Globosat, transmitido pela Sky e pela Net, foi criado para atender esse público carente de produtos e serviços personalizados.

A seguradora American Life também decidiu investir nesse segmento milionário ao lançar o primeiro seguro de vida para casais homossexuais do Brasil, denominado Vida Freedom. Ao observar o sucesso do seguro de vida Vida Freedom, a Tecnisa Construtora e Incorporadora ofereceu um ano de seguro grátis para cada casal homossexual que adquirisse um de seus imóveis e ainda afirma que, na hora de decidir o acabamento do imóvel, o casal homossexual gasta $25 \%$ a

REMark - Revista Brasileira de Marketing, São Paulo, v. 8, n. 1, p 43-69, jan./jun. 2009. 
mais do valor do apartamento em detrimento aos no máximo $12 \%$ dos casais heterossexuais (CUNHA, 2006).

Apesar de ser "um dos segmentos que mais tem se projetado no cenário brasileiro" (PEREIRA; AYROSA; OJIMA, 2005, p. 1), são quase inexistentes estudos sobre o comportamento dos homossexuais na área hoteleira. Essa lacuna na literatura afeta, desse modo, a atuação das empresas prestadoras de serviços que, em razão da grande quantidade de oferta de produtos e serviços, precisam compreender melhor seus clientes para obter certa vantagem sobre os concorrentes desse segmento (KOTLER; ARMSTRONG, 1999). Sendo o reconhecimento do indivíduo como gay visto como "uma identidade espiritual, emocional, física, política e, agora, econômica" (LUKENBILL, 1999, p. 41), os profissionais de marketing estão cada vez mais motivados a explorar e entender o consumidor gay (KATES, 1999).

O consumo começou a ser visto pelos pesquisadores como uma experiência, e não mais como uma simples forma de transação, logo passou a ser considerado como um "estágio subjetivo da consciência com uma variedade de significados simbólicos, respostas hedônicas e critérios estéticos" (HIRSCHMAN; HOLBROOK, 1982, p. 132). Com o aumento da produção em massa e os avanços tecnológicos, a funcionalidade essencial dos produtos e dos serviços diminuiu para abrir espaço para os significados simbólicos (ADDIS; HOLBROOK, 2001, p. 52). Assim, muito mais do que a normalidade das características físicas e benefícios funcionais do produto, os consumidores querem "produtos, comunicação e campanhas de marketing que estimulem os sentidos e mexam com as emoções e com a cabeça" (SCHMITT, 2002, p. 38). Faz-se, então, necessário, por parte dos gerentes de marketing, o conhecimento das emoções e sentimentos que os consumidores vivem na interação com os produtos da empresa, utilizando essa visão experiencial como uma importante ferramenta para entender o comportamento de seus consumidores e criar, assim, valor no momento do consumo (ADDIS; HOLBROOK, 2001; BERRY; CARBONE; HAECKEL, 2002; KNUTSON; BECK, 2003; PULLMAN; GROSS, 2003).

Apesar de existirem estudos sobre a influência do ambiente de serviços na experiência de consumo (BAGOZZI; GOPINATH; NYER, 1999; BAKER; CAMERON, 1996; BAKER; PARASURAMAN; GREWAL, 1994; BITNER, 1992; SALAZAR, 2006), não foi encontrada nenhuma pesquisa que estudasse como a atmosfera de hotéis interfere no comportamento de consumo dos homossexuais no Brasil. O estudo das características particulares do indivíduo como "idade, renda, sexo e cultura podem ser determinantes fundamentais de como as pessoas associam elementos atmosféricos" (BAKER; PARASURAMAN; GREWAL, 1994, p. 223), pois quanto mais

REMark - Revista Brasileira de Marketing, São Paulo, v. 8, n. 1, p 43-69, jan./jun. 2009. 
semelhante o estilo de vida dos consumidores, mais parecidas serão suas percepções da atmosfera (KOTLER, 1973). Assim sendo, os efeitos do ambiente dos serviços precisam ser examinados de acordo com as particularidades de cada consumidor ou segmento específico (BAKER; CAMERON, 1996).

Um estudo mais aprofundado sobre o fenômeno também poderia contribuir com as decisões gerenciais das empresas de serviços, pois o cenário físico do serviço pode ajudar ou obstruir o alcance dos objetivos organizacionais e as metas de marketing da empresa (BITNER, 1992). Segundo Haslop, Hill e Schimidt (1998), é essencial que os profissionais de marketing que desejarem atingir o público gay entendam a natureza simbólica e hedônica do ambiente de serviços. Dessa forma, os empresários que tomarem conhecimento dos elementos do ambiente que afetam positivamente seus consumidores poderão decidir com mais precisão as mudanças a serem realizadas, tais como a cor das paredes, as músicas escolhidas, a temperatura, a iluminação etc. Pois, para Baker e Cameron (1996), deveria ser prioridade dos administradores de serviços terem o conhecimento dos níveis dos elementos do ambiente mais apropriados e confortáveis para seus consumidores. Wakerfield e Blodgett (1996) concordam com Baker e Cameron (1996, p. 51) ao afirmar que aqueles gerentes que focalizarem o ambiente de serviços, além da simples oferta de serviços primários, terão "maior chance de maximizar os lucros atuais e de longo prazo". Apesar da negligência dos empresários em não considerar a atmosfera como um instrumento de marketing, o ambiente é "a mais relevante ferramenta de marketing quando o produto é direcionado a uma classe social distinta ou a um grupo de consumidores com estilos de vida parecidos” (KOTLER, 1973, p. 53). Conhecer melhor as reações dos clientes provocadas pelas variáveis da atmosfera de serviço é, portanto, primordial para auxiliar os empresários a investir nas variáveis mais eficazes para atingir a comunidade homossexual.

Portanto, percebe-se que é importante realizar estudos para entender os clientes homossexuais usuários dos serviços dos hotéis. Diante disso, esta pesquisa objetivou descrever os fatores do ambiente de hotéis que mais influenciam a experiência de consumo dos homossexuais entrevistados.

REMark - Revista Brasileira de Marketing, São Paulo, v. 8, n. 1, p 43-69, jan./jun. 2009. 


\section{AMBIENTE DE SERVIÇOS}

O pensamento administrativo tem avançado ao reconhecer que as pessoas respondem a mais do que simplesmente consumir produtos tangíveis ou serviços oferecidos no momento da decisão de compra, pois elas respondem ao pacote completo do consumo, o que inclui a característica mais importante: o local onde o produto é adquirido ou consumido (KOTLER, 1973). Dentre os

provedores-chave de experiência (como a comunicação, pessoas e identidade visual/verbal), encontram-se os ambientes físicos, que são utilizados como instrumentos estratégicos no marketing com a finalidade de produzir experiências sensoriais, afetivas, cognitivas e físicas (SCHMITT, 2002; WIKSTRÖM, 2004). A relevância do ambiente de serviços também aparece por sua inclusão como "um dos poucos componentes-chave nos extensamente reconhecidos conceitos do encontro do serviço" (BAKER; CAMERON, 1996, p. 338).

O ambiente de serviços é, portanto, uma ferramenta de marketing (BITNER, 1990; KOTLER, 1973), um elemento da imagem da loja (TURLEY; FUGATE, 1992), uma evidência (HOFFMAN; TURLEY, 2002) e um estímulo capaz de provocar reações nos consumidores (DONOVAN; ROSSITER, 1982; MEHRABIAN; RUSSELL, 1974).

\subsection{VARIÁVEIS DO AMBIENTE DE SERVIÇOS}

De acordo com Hoffman e Turley (2002), a atmosfera é composta tanto por elementos tangíveis, tais como a construção física do edifício, os dispositivos elétricos, decoração e outros, como pelos elementos intangíveis, que são as cores, a música e a temperatura. Para Turley e Milliman (2000), são esses os elementos capazes de levar o consumidor a um estado emocional cognitivo, provocando, assim, alguns comportamentos ou respostas.

Tendo em vista a lista interminável de fatores que compõem a atmosfera, Bitner (1992) subdividiu o ambiente de serviços em três dimensões. A primeira delas é formada pelas condições ambientais, que tratam das características do background: a música, a temperatura, a iluminação (BAKER; CAMERON, 1996; BAKER; PARASURAMAN; GREWAL, 1994; ZANELLA; CÂNDIDO, 2002), o barulho e o aroma (SCHMITT; SIMONSON, 2000). A segunda dimensão é denominada layout e funcionalidade do ambiente. O layout se refere à disposição de máquinas, equipamentos e móveis (PORIA, 2006) no ambiente e a funcionalidade, que é a capacidade que esses itens possuem de alcançar os objetivos e facilitar o desempenho do serviço. A terceira

REMark - Revista Brasileira de Marketing, São Paulo, v. 8, n. 1, p 43-69, jan./jun. 2009. 
dimensão apresentada por Bitner (1992) considera os sinais, símbolos e artefatos que compõem o interior e o exterior da empresa e são também considerados comunicadores explícitos da estrutura. Tal dimensão abrange a qualidade dos materiais utilizados na construção, artesanatos, objetos nas paredes, como fotografias e certificados, ou seja, todos os elementos decorativos (DUBE; LE BEL; SEARS, 2003; SCHMITT; SIMONSON, 2002).

Salazar (2006, p. 25) destaca que, além desses fatores, há uma relevância maior do ambiente social, que "compreende as relações entre os clientes e entre estes e os funcionários", principalmente nas empresas de serviço. Apesar de Bitner (1990) incluir os participantes na produção do serviço no mix de marketing, em seu estudo posterior (BITNER, 1992) não foram mencionadas as variáveis humanas. A participação dessas variáveis no conjunto de elementos que compõem o ambiente de serviços não pode ser negligenciada, pois a atmosfera da loja "influencia os consumidores e os empregados, que, por sua vez, pelas suas interações, influenciam uns aos outros" (TURLEY; MILLIMAN, 2000, p. 194).

Uma tipologia desenvolvida por Baker (1986, apud BAKER; PARASURAMAN; GREWAL, 1994), no entanto, abarca os fatores sociais juntamente com os fatores ambientais e de projeto. Os fatores ambientais e de projeto correspondem, respectivamente, às dimensões de condições ambientais e de layout/funcionalidade/decoração (BITNER, 1992). Os fatores sociais, por sua vez, são os atores que participam da produção do serviço, que são os consumidores e funcionários. São elementos do fator social o tipo, o número e o comportamento dos outros clientes no estabelecimento e a atuação dos empregados (BAKER; PARASURAMAN; GREWAL, 1994). As variáveis humanas também foram discutidas no estudo de Turley e Milliman (2000). Os autores incluíram as características do consumidor e dos funcionários, a aglomeração de consumidores no local, a privacidade e os uniformes vestidos pelos empregados.

A importância do lado social na troca mútua do serviço foi também considerada por Butcher (2005, p.126), principalmente nos serviços da hospitalidade, em que existe um grande contato entre os consumidores e os empregados. $\mathrm{O}$ autor definiu duas variáveis sociais (o conforto social e o valor social) capazes de influenciar o comportamento do consumidor e, consequentemente, os resultados do serviço, como as intenções de recompra. O conforto social foi definido como o "sentimento do consumidor de ansiedade ou relaxamento surgido da interação social com o empregado do serviço". Os sentimentos de conforto surgem a partir dos comportamentos dos outros no local, portanto, dentro das interações do serviço; são muitas vezes dependentes das ações dos

REMark - Revista Brasileira de Marketing, São Paulo, v. 8, n. 1, p 43-69, jan./jun. 2009. 
funcionários da hospitalidade. A segunda variável, o valor social, diz respeito ao sentimento de valoração e importância demonstrado pelos prestadores de serviços aos seus clientes na realização do serviço (BUTCHER, 2005).

Os empreendimentos hoteleiros também foram descritos como serviços de facilidades dirigidas (TURLEY; FUGATE, 1992). Segundo os autores, os hotéis dependem da habilidade dos consumidores de interagirem com o ambiente para produzirem uma experiência de consumo satisfatória. A atmosfera dos hotéis foi, também, considerada pelos autores como o único meio tangível que os consumidores têm para processar no momento da prestação do serviço. Especificamente os consumidores homossexuais procuram se sentir em casa durante o período da hospedagem (WAITT; MARKWELL, 2006), deixando para os hotéis maior responsabilidade para oferecer-lhes um ambiente propício. Por isso, os serviços relacionados ao lazer, tais como os hotéis, requerem geralmente que os consumidores passem períodos extensos de tempo nas dependências físicas do ambiente de serviços (WAKEFIELD; BLODGETT, 1999).

Knutson e Beck (2003) elaboraram um modelo teórico dividido em três partes específicas. A primeira parte do modelo é constituída pelo estágio da pré-experiência do consumo, que engloba as expectativas criadas pela marca, atividades promocionais, campanhas publicitárias e as memórias pessoais armazenadas em uma experiência anterior. A segunda parte foi considerada o coração do modelo e representa todas as experiências realizadas em tempo real nos encontros de serviço. Na hotelaria, essa parte do modelo está relacionada a todos os estágios por que os hóspedes passam, incluindo o momento da realização da reserva do hotel, aos procedimentos de check-in, estada e o check-out (HUGHES, 2002). A terceira parte do modelo é composta pela "pós-experiência", que se trata das percepções pessoais dos hóspedes em relação ao valor e à satisfação que eles atribuem à experiência.

\section{METODOLOGIA}

Considerando as premissas da pesquisa qualitativa de "procurar descobrir e entender um fenômeno, um processo ou perspectivas e visões de mundo das pessoas envolvidas" (MERRIAM, 1998, p. 11), utilizou-se essa perspectiva na realização deste estudo.

Foram entrevistados seis homossexuais, do gênero masculino, residentes na cidade do Recife. Como critério de seleção desses sujeitos, decidiu-se que eles também teriam de possuir

REMark - Revista Brasileira de Marketing, São Paulo, v. 8, n. 1, p 43-69, jan./jun. 2009. 
algum curso superior completo ou em andamento. Além disso, foi relevante os respondentes se definirem como gays, pois "o fato de um homossexual ser assumido tem grande influência em seu comportamento de consumo" (NUNAN, 2003, p. 202), para que os entrevistados não se sentissem constrangidos durante a coleta de dados.

A fim de selecionar as pessoas para serem entrevistadas, após a identificação do primeiro respondente, utilizou-se a técnica chamada snowball sampling (amostragem por bola de neve), na qual um participante da pesquisa é conhecido do pesquisador (NUNAN, 2003) e, posteriormente, o investigador solicita aos respondentes a indicação de sujeitos sociais que possam contribuir para a pesquisa (MCDANIEL; GATES, 2005). É importante salientar que "esse tipo de amostragem só funciona com populações cujos membros se conheçam entre si, a exemplo da comunidade gay" (NUNAN, 2003, p. 204).

Salienta-se que, diferentemente da perspectiva quantitativa, que trabalha com amostras maiores por buscar generalizações estatísticas, a abordagem qualitativa preocupa-se com o exame detalhado do fenômeno, selecionando, assim, menor número de pessoas para se ter condições de aprofundar o estudo e alcançar alto nível de análise. Desse modo, quando as categorias que explicavam o fenômeno estudado emergiram com consistência, percebeu-se que o número de entrevistados já era suficiente (MERRIAM, 1998).

Por se tratar de estudo qualitativo, foi escolhida a entrevista semiestruturada (GRESSLER, 2004; PATTON, 2001) como instrumento de coleta de dados, por permitir o aprofundamento do tema pesquisado e por parecer mais adequada para que os aspectos do comportamento de consumo dos homossexuais pudessem ser descritos, compreendidos e interpretados (NUNAN, 2003).

Por essa técnica, cada um dos seis respondentes foi entrevistado uma vez, em ambientes variados, no período de um mês, entre agosto e setembro de 2006. Todas as entrevistas aconteceram na cidade do Recife, foram gravadas digitalmente e logo depois transcritas na íntegra. É importante mencionar que os entrevistados não estão identificados por seus respectivos nomes próprios para preservar a sua confidencialidade. Assim, foram utilizados nomes fictícios, embora próprios da pessoa humana.

Por fim, apresenta-se a análise dos dados, levando-se em consideração a perspectiva qualitativa. Nesse mister, foram examinados os relatos dos respondentes, sendo os dados interpretados com base na fundamentação teórica que embasou este trabalho. Com isso,

REMark - Revista Brasileira de Marketing, São Paulo, v. 8, n. 1, p 43-69, jan./jun. 2009. 
identificaram-se categorias que emergiram dos relatos dos entrevistados que respondessem ao questionamento do problema de pesquisa.

\section{DISCUSSÃO DOS RESULTADOS}

As categorias que serão apresentadas a seguir emergiram espontaneamente das entrevistas realizadas durante a pesquisa. Para melhor compreender quais são os fatores do ambiente de hotéis que mais influenciam o comportamento de consumo dos homossexuais entrevistados, a seção seguinte apresentará os resultados com o apoio do modelo de Bitner (1992), que agrupa as dimensões do ambiente em condições ambientais, espaço e funcionalidade; e sinais, símbolos e artefatos. Além desse modelo, foram utilizadas as abordagens teóricas que complementam o modelo de Bitner (1992), tais como a categorização do fator limpeza explicadas por Turley e Milliman (2000), que está ligada às variáveis interiores do ambiente. Também foi utilizado o modelo proposto por Knutson e Beck (2003), para classificar os serviços prestados pelos hotéis como benefícios extrínsecos na experiência de consumo e a classificação do fator funcionários como um fator social do ambiente, de acordo com o estudo de Baker, Parasuraman e Grewal (1994).

\begin{tabular}{|c|c|c|}
\hline BASE TEÓRICA & $\begin{array}{c}\text { DIMENSÕES DO } \\
\text { AMBIENTE }\end{array}$ & $\begin{array}{c}\text { CATEGORIAS EMERGIDAS } \\
\text { NA PESQUISA }\end{array}$ \\
\hline $\begin{array}{c}\text { Bitner (1992), Turley e } \\
\text { Milliman (2000) }\end{array}$ & Condições ambientais & $\begin{array}{c}\text { Iluminação } \\
\text { Aroma } \\
\text { Limpeza }\end{array}$ \\
\hline Bitner (1992) & Espaço e funcionalidade & $\begin{array}{c}\text { Área de preferência } \\
\text { Funcionalidade }\end{array}$ \\
\hline Bitner (1992) & Sinais, símbolos e artefatos & Decoração \\
\hline $\begin{array}{c}\text { Knutson e Beck (2003) } \\
\text { Baker, Parasuraman e Grewal } \\
(1994)\end{array}$ & Fator social do ambiente de \\
hotéis & $\begin{array}{c}\text { Café da manhã } \\
\text { TV a cabo }\end{array}$ \\
\hline
\end{tabular}

Quadro 1 - Fatores influenciadores do consumo de serviços hoteleiros por homossexuais Fonte: Elaborado pelos autores.

REMark - Revista Brasileira de Marketing, São Paulo, v. 8, n. 1, p 43-69, jan./jun. 2009. 
Durante a análise dos dados, cada dimensão do ambiente de serviço foi investigada com apoio do embasamento teórico (ver Quadro 1). A descrição desses resultados será apresentada a seguir.

\subsection{CONDIÇÕES AMBIENTAIS}

As condições ambientais, segundo Bitner (1992, p. 66), em “as características por trás do ambiente, como a temperatura, iluminação, barulho, música e cheiro”. Nesta seção, serão abordadas as condições ambientais que mais se sobressaíram nesta pesquisa, ou seja, a iluminação, o aroma e a limpeza são as que mais influenciaram o comportamento de consumo dos homossexuais entrevistados.

\subsubsection{ILUMINAÇÃO}

A iluminação foi apontada como um elemento relevante do ambiente para o consumo gay. Segundo os teóricos, o tipo e a intensidade da luz influenciam o ânimo e a disposição dos indivíduos. Por essa razão, a "luz mais intensa produz sensações estimulantes, enquanto uma iluminação mais fraca é tranquilizante e confortante" (ZANELLA; CÂNDIDO, 2002, p. 17). De fato, dois homossexuais entrevistados afirmaram gostar da iluminação dos apartamentos por ela ser controlável. Quando foi perguntado a Gabriel Montenegro sobre a iluminação, ele afirmou: "Eu gosto da iluminação. [...] em Milão tinha uma iluminação que, era assim, tinha vários tipos de iluminação, você ligava aí ficava uma luz que ficava centrada, dependendo de como você colocasse".

Nota-se, portanto, que o controle dos níveis de iluminação é importante para os homossexuais entrevistados. Isso corrobora a proposição de Baker e Cameron (1996, p. 340), a qual considera que "existe uma relação entre níveis de preferência da iluminação, a situação social e a quantidade de atenção visual requerida por uma atividade". Os autores também acreditam que "os indivíduos preferem um nível base de iluminação adequada para a atividade envolvida”. Isso foi observado nesta pesquisa, pois a possibilidade de controlar a iluminação de acordo com a situação fez com que os homossexuais entrevistados respondessem positivamente à experiência de consumo em hotéis.

REMark - Revista Brasileira de Marketing, São Paulo, v. 8, n. 1, p 43-69, jan./jun. 2009. 
Pedro Araújo apontou a iluminação como um fator de sua preferência, demonstrando que também gosta da iluminação dos apartamentos por ser controlável e por ser constituída por diferentes recursos de iluminação.

O destaque que os homossexuais entrevistados deram à iluminação confirma, dessa maneira, as constatações da pesquisa de Baker, Parasuraman e Grewal (1994), a qual mostra que a iluminação pode interferir na percepção de qualidade do serviço. Uma contribuição que se percebe a partir desses resultados é o fato da iluminação ser um elemento controlável nos apartamentos de hotéis, o que é visto pelos homossexuais como algo positivo, pois eles podem criar a atmosfera mais propícia, dependendo da ocasião.

\subsubsection{AROMA}

A memória para cheiros talvez seja uma das mais fortes que o ser humano possui. Por esse motivo, muitos detalhes penosos de uma experiência são lembrados quando o cheiro é percebido durante essa experiência (SCHMITT; SIMONSON, 2000). Essa afirmação corrobora os resultados obtidos na pesquisa, pois Gabriel Montenegro, ao recordar uma experiência negativa em um convento transformado em hotel, ressalta: “[...] o convento funcionava com as instalações de um hotel, atendendo muito bem, o banheiro era um ovo com um cheiro horrível, mas o convento era bonitinho, dentro era simples". Mesmo considerando o hotel bom em outras características físicas, para Gabriel Montenegro o cheiro desagradável do banheiro foi bastante memorável.

Confirmando o pensamento de Kotler (1973, p. 51), que acredita que "a atmosfera pode ser descrita em termos sensoriais" e que uma das principais dimensões do olfato é o cheiro, um dos prérequisitos para que João da Silva realize uma reserva em um hotel é a divisão dos andares em fumantes e não fumantes: "Os hotéis têm se preocupado muito em dividir seus andares em fumantes e não fumantes, isso pra mim tem sido uma regra fundamental".

A declaração de João da Silva também confirma a proposição de Hoffman e Turley (2002), a qual considera que as variáveis do ambiente podem influenciar os consumidores que estão vivenciando a mesma experiência ao mesmo tempo com outros clientes. Por esse motivo, segundo os autores, o ambiente deve ser construído de modo que possa evitar conflitos e isso foi percebido pelo entrevistado como um fator positivo em suas experiências em hotéis.

Por outro lado, o que incomoda Pedro Assis é o cheiro de mofo no apartamento. Quando lhe foi pedido que descrevesse como deveria ser o apartamento, o entrevistado afirmou que: "Não pode

REMark - Revista Brasileira de Marketing, São Paulo, v. 8, n. 1, p 43-69, jan./jun. 2009. 
ter aquele cheiro de mofo". Contudo, a ausência de cheiro nos enxovais parece também incomodar um dos entrevistados: "Uma coisa que eu não gosto de hotéis é o cheiro seco de toalha, por que eles não perfumam, não é? Os lençóis e as toalhas, eles vêm com um cheiro seco que eu não gosto [...]" (Gabriel Montenegro).

Assim, percebe-se que o cheiro está intimamente relacionado com a limpeza e à conservação dos apartamentos e que é preferível ter enxovais de cama e banheiro perfumados.

\subsubsection{LIMPEZA}

Percebeu-se que a questão da limpeza nos hotéis, em geral, é essencial para que os homossexuais permaneçam, retornem ou escolham um hotel. Tal fator foi constatado no estudo de Wakefield e Blodgett (1999), que mostra que a limpeza é um determinante importante na percepção da qualidade do ambiente de serviços, sobretudo, naquelas situações em que os consumidores passam muitas horas nesse ambiente. Essa característica do ambiente também foi considerada por eles, como sendo uma questão importante, especialmente pelas clientes do gênero feminino e, como os homossexuais masculinos, "definindo sua sexualidade pela escolha daqueles de seu próprio sexo, eles se identificam com mulheres" (KATES, 1998, p. 17).

A limpeza nos apartamentos e no banheiro, segundo esta pesquisa, também é um fator importante na experiência de consumo dos homossexuais. Tal constatação foi obtida por meio da afirmação de João da Silva, pois a primeira coisa que ele percebe quando entra em um apartamento é a limpeza, e argumenta: "Indiscutivelmente, a primeira coisa que eu olho, percebo, quando eu entro num quarto, é a aparência do quarto, limpeza principalmente, porque eu sou alérgico, então, esse tipo de coisa, mofo, poeira, me incomoda bastante". Para Gabriel Montenegro a higiene do banheiro também é importante. Ele afirma: "Morro de nojo de um banheiro sujo [...]". Essa afirmação vai de encontro ao estudo realizado por Baker, Parasuraman e Grewal (1994), o qual considera que os fatores estéticos e de projeto do ambiente, dentre eles, a limpeza, não influenciam as inferências de qualidade do serviço.

Quando foi perguntado a Eduardo Assis se ele já havia vivenciado alguma experiência negativa em hotéis, o entrevistado também ressaltou a questão da higiene do banheiro do apartamento: "O banheiro não era higiênico [...]". Destaca-se, que a higiene dos banheiros nos apartamentos de hotéis é um fator determinante na associação de uma experiência positiva ou negativa dos homossexuais entrevistados.

REMark - Revista Brasileira de Marketing, São Paulo, v. 8, n. 1, p 43-69, jan./jun. 2009. 


\subsection{ESPAÇO E FUNCIONALIDADE}

No modelo de Bitner (1992), essa dimensão se refere à maneira como os equipamentos e móveis são arranjados, seus tamanhos e formas no ambiente de serviços. Observou-se que a cama, a área de preferência e a funcionalidade são os fatores que mais influenciam a experiência de consumo dos homossexuais entrevistados.

\subsubsection{MÓVEIS: CAMA}

Durante os relatos dos entrevistados, a cama do apartamento de hotel apareceu com maior evidência. Para os homossexuais entrevistados no estudo de Poria (2006, p. 332), "o tamanho da cama não tem nada a ver com sua funcionalidade", ou seja, para eles não importava se a cama era grande ou pequena, mas sim que fosse uma cama de casal. Os homossexuais entrevistados no Recife não apenas querem uma cama grande, mas para eles tanto o tamanho quanto o conforto da cama são essenciais durante sua experiência de consumo em hotéis. Essa afirmação pôde ser observada pela descrição de Antônio Cavalcanti: "A cama tem que ter um colchão legal, tem que ter um travesseiro nem muito alto nem muito baixo, na medida certa, tem que ter edredom para se cobrir e não sentir muito frio [...]”.

A cama também é uma questão importante para João da Silva: "se a cama for boa, for macia, os travesseiros, o banheiro for limpo e tudo, então está tranquilo". E, quando foi questionado o que seria uma cama boa, João da Silva completou: “Aquela que não me incomode, macia, confortável [...]". Para Eduardo Assis esse fator também é um elemento fundamental para que a experiência nos hotéis seja positiva, quando ele afirma que: "Tem que ter uma cama confortável”. As declarações dos entrevistados confirmam o pensamento de Kotler (1973), o qual considera que a atmosfera pode ser descrita por meio dos canais sensoriais táteis, tais como a maciez. Desse modo, a cama nos apartamentos dos hotéis deve ser grande (Pedro Araújo), macia (João da Silva) e confortável (Pedro Araújo, Eduardo Assis, João da Silva), para que haja uma experiência de consumo positiva.

\subsection{2 ÁREA DE PREFERÊNCIA}

Percebeu-se que houve uma diferença quanto à preferência dos ambientes de hotéis entre os homossexuais acompanhados por pessoas heterossexuais, tais como parentes e amigos, e os homossexuais hospedados com seus respectivos parceiros. Os respondentes que se hospedavam

REMark - Revista Brasileira de Marketing, São Paulo, v. 8, n. 1, p 43-69, jan./jun. 2009. 
com seus companheiros diziam que era no apartamento onde mais gostavam de ficar, enquanto os homossexuais que tinham como companhia outros heterossexuais preferiam passar mais tempo nas áreas de lazer dos hotéis. No depoimento de João da Costa, por exemplo, ele afirma ter retornado a um hotel com seu parceiro pelo fato de ser simples, e forneceu as características do apartamento: "tinha um quarto com ar-condicionado, uma televisão, uma cama, um banheiro e pronto". No entanto, quando viajou com seus pais, João da Costa ficava mais tempo no lobby e na região da sala de jogos do hotel. Sobre esses ambientes, ele ressaltou: "Aquela coisa, porque era um hotel grande, era o Othon, quando você chega é aquela coisa bem chique com colunas de mármore e tinha inclusive lojas: a Zara, Clock's, tinha várias lojas [...] Ficava mais também na região da sala de jogos, mas eu ficava mais no lobby, tinha televisão, TV a cabo, e era bem luxuoso".

$\mathrm{Na}$ entrevista com Pedro Araújo, tal fato também foi constatado, quando ele afirmou que: "Quando eu viajava com os pais, influenciava mais a estrutura física do hotel em termos de lazer, porque o objetivo talvez fosse outro [...]". Quando foi perguntado onde ele mais gostava de ficar quando viajava com seus pais, Pedro Araújo respondeu: "Na área de lazer mesmo, piscina, sala se jogos, talvez se tivesse um ambiente de bar”. As afirmações dos entrevistados nas situações em que estavam acompanhados por heterossexuais confirmam o modelo proposto por Knutson e Beck (2003), o qual demonstra que a experiência em hotéis é também influenciada pela interação com os outros indivíduos.

Pôde-se, desse modo, entender que é na área de lazer que os homossexuais, quando não estão acompanhados por outros homossexuais, mais gostam de ficar. Isso pode estar relacionado com as afirmações de Backer e Cameron (1996), as quais consideram que, quando os consumidores desejam interagir com os outros clientes do local, a presença de outras pessoas no ambiente resulta em comportamentos positivos, porque essas pessoas preenchem o tempo livre no local. Contudo, mesmo assim, foi observado que todos os homossexuais entrevistados passam mais tempo no apartamento dos hotéis, seja para conversar com amigos heterossexuais, seja para aproveitar o momento de privacidade com seus parceiros.

REMark - Revista Brasileira de Marketing, São Paulo, v. 8, n. 1, p 43-69, jan./jun. 2009. 


\subsubsection{FUNCIONALIDADE}

Existe também uma preferência pelos hotéis que dispõem de uma estrutura formada para cozinhar e armazenar alimentos por parte dos consumidores homossexuais. Essa necessidade pode estar aliada ao fato de os homossexuais procurarem se sentir em casa durante as suas viagens (WAITT; MARKWELL, 2006). Para João da Silva, o apartamento do hotel deve oferecer uma funcionalidade maior, para que ele se sinta mais confortável, por isso prefere os hotéis tipo flat. Ele explica: "A funcionalidade dos hotéis, eu gosto muito de flats. Os flats são hotéis que geralmente têm cozinha, um fogãozinho, geladeira, armários [...]”.

Essa preferência por apartamentos tipo flat pelo respondente também está em consonância com o estudo de Bitner (1992), o qual advoga que a funcionalidade é um fator do ambiente de serviços que mais influencia o comportamento de consumo nos ambientes do tipo self-service, onde os consumidores realizam suas atividades sem a assistência dos funcionários.

Antônio Cavalcanti também relatou uma experiência memorável para ele, ocorrida em uma das vezes em que se hospedou em um hotel, que diz respeito à funcionalidade encontrada no apartamento: "Era o seguinte: o apartamento tinha uma cozinha pequena, geladeira, com forno micro-ondas, uma torradeira, e a gente é que fazia a comida, com cafeteira, tudo, um fogão elétrico para esquentar as coisas, mas estava lá o café, o chá, o leite, então, era a gente que fazia. Foi legal por isso, porque você fica com certa liberdade do que você quer [...]”.

A afirmação do entrevistado reforça o estudo de Wakefield e Blodgett (1999), os quais afirmam que um ambiente de serviços apresentado de forma interessante e efetivo pode atender às necessidades hedônicas e prazerosas do consumidor. Neste caso, a funcionalidade dos apartamentos de hotéis, principalmente os considerados do tipo flat, atende a necessidade hedônica dos entrevistados, por possibilitar-lhes sentir-se em casa e, assim, atuarem com maior liberdade.

\subsection{SINAIS, SÍMBOLOS E ARTEFATOS}

Essa dimensão da atmosfera de serviços se refere aos componentes expostos no ambiente, tais como placas, quadros, artefatos pessoais, estilo e decoração (BITNER, 1992). A decoração foi o fator dessa dimensão identificado como o mais importante para os homossexuais entrevistados.

REMark - Revista Brasileira de Marketing, São Paulo, v. 8, n. 1, p 43-69, jan./jun. 2009. 


\subsubsection{DECORAÇÃO}

Muitos dos entrevistados especificaram que preferem a decoração clean nos hotéis. A palavra clean significa limpo em inglês e, como estilo provoca "associações mentais e emocionais" (SCHMITT; SIMONSON, 2000, p. 101). Deve ser por esse motivo que os homossexuais entrevistados preferem esse tipo de decoração, pela sensação de limpeza que o ambiente proporciona. Tal fato pôde ser observado na declaração de Antônio Cavalcanti: “Quando o móvel é escuro dá sensação de que é mais sujo, que é mais velho talvez, então assim, um quarto mais clean dá uma sensação melhor pra mim”.

Essa afirmação do entrevistado está em conformidade com o estudo de Dube, Le Bel e Sears (2003), que afirmam que o estilo do apartamento é o componente da hospedagem que tem a capacidade de proporcionar o conforto na estada. Para Pedro Araújo, a decoração é um dos primeiros elementos da estrutura física dos hotéis que observa e descreve como deveria ser uma decoração moderna: "Um ambiente mais padrão assim, uma coisa que siga o padrão, que você vê que foi um decorador, um arquiteto, que trabalhou no lugar".

Pode-se, dessa maneira, compreender que a escolha pela decoração clean pelos homossexuais entrevistados está intimamente ligada à sensação de limpeza e conservação do hotel como um todo, pois as cores do ambiente criam identificações e associações nos consumidores (SCHMITT; SIMONSON, 2000). As declarações dos participantes também corroboram as afirmações de Wakefield e Blodgett (1999), que consideram a decoração como um dos principais fatores que "contribuem com a atratividade do ambiente de serviços", e, segundo sua pesquisa, influencia os clientes no quesito percepção de qualidade do ambiente de serviços.

\subsection{BENEFÍCIOS EXTRÍNSECOS}

De acordo com o modelo de Knutson e Beck (2003), as experiências em hotéis também são influenciadas positivamente pelos benefícios extrínsecos oferecidos. Dado que não são todos os hotéis que oferecem café da manhã e disponibilizam TV a cabo nos apartamentos, esses serviços foram considerados pelas pesquisadoras como um benefício extrínseco que os hotéis podem oferecer.

REMark - Revista Brasileira de Marketing, São Paulo, v. 8, n. 1, p 43-69, jan./jun. 2009. 


\subsubsection{CAFÉ DA MANHÃ}

Todos os entrevistados apontaram o café da manhã, em seus relatos, como sendo um elemento decisivo em uma experiência positiva vivida em hotéis. Desse modo, percebe-se que os homossexuais entrevistados dão muito valor ao café da manhã em um hotel, e isso implica decisão da reserva e retorno ao mesmo hotel. Contudo, de acordo com o estudo de Poria (2006), o único atributo que o café da manhã deveria ter para que os homossexuais se sentissem satisfeitos, seria o fato de ser servido por um tempo mais prolongado. Nesta pesquisa, no entanto, as características mais relevantes de um café da manhã são tanto as variedades de opções quanto a qualidade dos alimentos. Isso pode ser evidenciado com o relato de um dos entrevistados. Ele reservou um apartamento por causa da foto do café da manhã que estava na internet: “[...] eu fiquei nesse hotel por causa da foto do café da manhã do hotel. Aí eu quero esse café da manhã, eu adoro café da manhã em hotel! [...]”.

Em outro momento, o mesmo entrevistado contou como gostou do café da manhã em um hotel em que se hospedou: "O café da manhã não era um café da manhã, era uma coisa absurda, parecia o centro de convenções, tinha tudo que você pode imaginar, todo tipo de comida [...]”.

Além de considerar o café da manhã importantíssimo, Antônio Cavalcanti, outro respondente, descreve como deveria ser o café da manhã para ele: "Eu acho que o café da manhã tem que ser diversificado, porque é diferente, né? [...] então, quando você chega num hotel você quer uma coisa diferente. Eu acho assim, que a variedade de frutas é uma coisa importante [...]”.

Eduardo Assis deu mais destaque à qualidade das comidas oferecidas no café da manhã e comentou sobre uma experiência positiva durante uma hospedagem: "Chega no café da manhã a comida é boa [...], mais uma comida benfeita, bem preparada". Isso confirma a pesquisa realizada por Clift e Forrest (1999, apud HUGHES, 2002), na qual constataram que os homossexuais dão importância à qualidade da comida. Nota-se aí que, além da diversidade dos alimentos servidos, é preciso que a comida também seja bem preparada.

\subsubsection{TV A CABO}

Todos os entrevistados declararam que o serviço de canais de TV a cabo é essencial dentro de um apartamento de hotel. Antônio Cavalcanti explica por que a TV a cabo é um serviço importante nos apartamentos de hotéis: “TV a cabo, você tem a opção de ver um filme, programas

REMark - Revista Brasileira de Marketing, São Paulo, v. 8, n. 1, p 43-69, jan./jun. 2009. 
diferentes [...]". João da Silva enfatizou a importância da televisão a cabo para que se hospede em um hotel: "Eu acho que é fundamental, quando eu falo em TV você associa à TV a cabo, TV aberta hoje, não é que ela não compensa, ela não traz mais um diferencial [...]"

As afirmações dos entrevistados confirmam o estudo de Wakefield e Blodgett (1999), no qual consideram que os ambientes de serviços que dispõem de equipamentos eletrônicos para o entretenimento podem fazer com que a estada se torne mais satisfatória.

\subsection{FATOR SOCIAL DO AMBIENTE DE HOTÉIS}

Segundo Baker, Parasuraman e Grewal (1994), o fator social corresponde à interação dos indivíduos presentes no ambiente de consumo. Nesta pesquisa, o elemento mais importante desse fator, para os homossexuais entrevistados, foi o comportamento dos funcionários dos hotéis.

\subsubsection{FUNCIONÁRIOS DOS HOTÉIS}

Segundo os entrevistados da pesquisa, suas experiências nos hotéis têm sido boas (Eduardo Assis; Gabriel Montenegro; João da Costa; Pedro Araújo) e tranquilas (Antônio Cavalcanti; João da Silva), enfatizando o fato de nunca terem sido mal tratados ou discriminados de alguma forma pelos funcionários dos hotéis.

Os resultados das entrevistas parecem estar em consonância com o estudo de Poria (2006), o qual advoga que os gays desejam ser tratados do mesmo modo que os clientes heterossexuais. Quando questionados sobre como os funcionários de um hotel deveriam se comportar, ou se os funcionários deveriam ter algum comportamento em especial, Pedro Araújo respondeu que: “Como se comportam. Acho que tem que ser o mais discreto possível, atendimento normal, deixar o mais confortável possível". Antônio Cavalcanti respondeu que não é necessário nenhum tratamento especial: "Não, acho que as pessoas não têm que estar se preocupando com isso não [...] Acho que discrição".

A questão da discrição é um ponto fundamental para os homossexuais entrevistados. João da Silva descreve como seria um bom atendimento dos funcionários de um hotel: "Atendimento personalizado, educação, a postura, a prontidão em atender, a questão da própria delicadeza com a situação, a discrição para mim é fundamental, então o máximo de profissionalismo e o mínimo de intimidade [...]".

REMark - Revista Brasileira de Marketing, São Paulo, v. 8, n. 1, p 43-69, jan./jun. 2009. 
Esse relato do entrevistado confirma o estudo de Knutson e Beck (2003, p. 29). Os autores afirmam que o "serviço que reflete a personalidade do cliente acrescenta no valor intrínseco da experiência". Os autores também explicam que "o grau de personalização do que o produto ou serviço oferece para o consumidor terá um efeito no valor intrínseco de uma experiência" e especificam que personalização não significa chamar o cliente pelo nome, mas sim um serviço autêntico que atenda as necessidades do cliente no momento.

O depoimento de João da Silva também está em consonância com o estudo de Butcher (2005). O autor defende que o conforto social deriva do comportamento dos funcionários no ambiente da hospitalidade, podendo fazer com que o cliente se sinta relaxado ou ansioso durante a interação com o funcionário. No caso de João da Silva, um bom atendimento, ou seja, uma interação positiva com os funcionários do hotel, pode fazer com que ele continue hospedado no mesmo local por mais tempo ou volte a se hospedar nele.

Outra questão é que alguns entrevistados afirmaram que já foram colocados em apartamentos com duas camas de solteiro e não com uma cama de casal. Apesar de ser um inconveniente para os homossexuais, pelo fato de ter que juntar as camas, isso não influenciou negativamente a experiência de consumo dos entrevistados. Pedro Araújo, por exemplo, reservou um apartamento com cama de casal, mas quando chegou mais cedo para verificar o apartamento, havia duas camas de solteiro.

Essa declaração do respondente confirma o estudo de Dube, Le Bel e Sears (2003). Os pesquisadores demonstraram que o desempenho dos funcionários é o atributo mais importante dos hotéis para que uma hospedagem seja considerada livre de preocupações. Contudo, o despreparo dos funcionários em lidar com o homossexualismo não impediria Pedro Araújo de voltar ao mesmo estabelecimento: "Mas eu voltaria, não seria nada que me impedisse não".

Essa situação refuta parcialmente a pesquisa de Poria (2006). Houve frustração com o serviço do hotel, mas essa frustração não impediria João da Costa de retornar ao mesmo hotel e ele aconselha: "Eles deveriam perguntar: vocês vão querer cama de casal ou duas camas para solteiro? Mas, quando vão dois meninos, eles já colocam cama para solteiro”.

REMark - Revista Brasileira de Marketing, São Paulo, v. 8, n. 1, p 43-69, jan./jun. 2009. 


\section{CONSIDERAÇÕES FINAIS}

Acredita-se que uma das principais contribuições que este estudo fornece ao meio acadêmico e prático é a relevância atribuída pelos homossexuais à limpeza dos apartamentos dos hotéis, e, mais especificamente, dos banheiros. Esse achado poderá ajudar as empresas de bens e serviços, que tenham a intenção de atingir esse público, a dar maior importância para a higienização e a escolher com mais cautela o material utilizado, ou seja, primar pela gestão da qualidade. Essa preocupação com a limpeza nos apartamentos também reflete na preferência pelos homossexuais pela decoração clean. Como esse tipo de decoração (caracterizada por poucas aglomerações de móveis e uso de cores claras) transmite ao consumidor a sensação que o ambiente é um local limpo, os homossexuais associam a decoração clean à limpeza de fato do ambiente, fator esse de grande relevância para o público homossexual entrevistado.

Dois elementos relevantes para os homossexuais como referência de experiências positivas durante suas hospedagens em hotéis foram o café da manhã e a TV a cabo. Os homossexuais gostam de sair de seu cotidiano, e é no café da manhã de hotéis que eles desfrutam de uma alimentação mais variada e de maior qualidade. Como a hospedagem em hotéis é um fenômeno simbólico para os homossexuais (PORIA, 2006), a TV a cabo é um serviço necessário, pois, como passam mais tempo no apartamento com seus companheiros, é uma maneira de se sentirem mais confortáveis. Tal fato pode ser relacionado com os pressupostos do marketing experiencial que tem o simbolismo no momento do consumo como uma de suas características marcantes (SCHMITT, 2002; WIKSTRÖM, 2004). Outro resultado importante que a pesquisa obteve foi a ausência de atitudes de discriminação por parte dos funcionários dos hotéis. No entanto, percebe-se que a mentalidade do hotel em relação à existência de casais homossexuais ainda está incipiente, ou até mesmo, primitiva. Muitos dos hotéis, de acordo com a pesquisa, não percebem que duas pessoas do mesmo sexo podem querer uma cama de casal no apartamento e, por esse motivo, não perguntam no ato da reserva a preferência do casal. Apesar dos homossexuais entrevistados não se incomodarem em juntar as camas de solteiro, seria importante que os gestores dos hotéis percebessem essas peculiaridades para melhor atender seus hóspedes. Ao conhecer os fatores que provocam maior estímulo de compra nos homossexuais pelos administradores, estes podem ser capazes de executar outras ações estratégicas para atingir esse público, tais como: criação de produtos e serviços, treinamentos para os funcionários para melhor atendê-los, planejamento de ações de marketing para atrair mais consumidores homossexuais, entre outros.

REMark - Revista Brasileira de Marketing, São Paulo, v. 8, n. 1, p 43-69, jan./jun. 2009. 
Mesmo sendo parte de uma subcultura de consumo, muitas vezes tratados diferente pelos heterossexuais, os homossexuais gostariam de receber o mesmo tratamento, de modo igual a qualquer outro hóspede nos hotéis. Eles prezam muito a postura discreta do funcionário que os atende. Esse relacionamento positivo com os funcionários dos meios de hospedagem pode proporcionar, como foi exposto, um conforto social por parte dos homossexuais.

Diante desses resultados, percebe-se que o ambiente de hotéis influencia a experiência de consumo homossexual, sendo uma realidade relevante para a prática empresarial e para o desenvolvimento de estudos científicos. Isso porque no âmbito da prática administrativa, deve-se considerar que o mercado GLS é constituído por $10 \%$ da população brasileira, o que significa 18 milhões de consumidores em busca de produtos e serviços personalizados, e gastam cerca de $30 \%$ a mais do que os consumidores heterossexuais (CUNHA, 2006). Além disso, a população homossexual foi caracterizada por Delozier e Rodrigue (1996), Fugate (1993) e Kates (1999), como sendo jovem, com alto poder aquisitivo, de bom nível educacional, informada política e socialmente, dedicada à carreira profissional, interessada em moda e disposta a gastar dinheiro. Assim sendo, acredita-se que os meios de hospedagem que decidirem investir nesse mercado precisam, portanto, conhecer com mais profundidade as relações de consumo desse público com os serviços oferecidos.

Em razão do grande potencial de compra oferecido pela comunidade homossexual, Newman e Nelson (1996, p. 58) argumentam que os profissionais de marketing "estão começando a reconhecer a homossexualidade como um modo de vida" e, por esse motivo, estão mostrando uma crescente atenção na criação e exibição de mensagens e propagandas especialmente para esse público. Embora a existência do mercado homossexual ter sido constatada na prática por profissionais de marketing, teóricos que estudam o comportamento de consumo de subculturas específicas têm praticamente ignorado o assunto. Complementando esse pensamento, Oliveira (2002, p. 33) acredita que "ignorar esse nicho é um grande equívoco mercadológico e acadêmico", por esse motivo o mercado homossexual não deve, assim, ser negligenciado pelos profissionais de marketing (DELOZIER; RODRIGUE, 1996, p. 210).

No campo teórico, Peñazola (1996) explica que é provável que existam diferenças nos significados e na maneira de como os produtos e serviços são utilizados entre homossexuais e heterossexuais, no entanto, "poucas pesquisas foram conduzidas para explorar as diferenças de atitudes e comportamentais entre os homossexuais" (NEWMAN; NELSON, 1996, p. 57). Já que os significados e práticas pertencentes à sociedade dominante não podem ser abrangidos para a

REMark - Revista Brasileira de Marketing, São Paulo, v. 8, n. 1, p 43-69, jan./jun. 2009. 
população gay (NEWMAN; NELSON, 1996, p. 58), torna-se necessário "ampliar as medidas de padrões de consumo para levar em consideração as diferenças nos significados e usos de acordo com vários produtos, serviços e estímulos de marketing entre as várias subculturas de consumo" (PENÃZOLA, 1996, p. 23), principalmente no que se refere à indústria da hospitalidade. Os estudos relacionados com o turismo têm se utilizado de explicações teóricas universais, não prestando, assim, muita (ou quase nenhuma) atenção para as variações de "classe, etnia, gênero ou sexualidade" (WAITT; MARKWELL, 2006, p. 10). Além disso, os estudos existentes se preocuparam principalmente com o comportamento de consumo dos homossexuais em lojas varejistas, o que revela uma carência na literatura (NUNAN, 2003; PEREIRA; AYROSA; OJIMA, 2005).

Visto que poucas pesquisas teóricas e empíricas foram conduzidas com o intuito de investigar o impacto da atmosfera na experiência de consumo nos serviços, torna-se adequado sugerir que se poderia ganhar muito ao analisar o papel da atmosfera no encontro do serviço (HOFFMAN; TURLEY, 2002). Anos atrás, essa insuficiência de estudos nessa área também já tinha sido observada por Turley e Fugate (1992), quando afirmaram que a variável lugar não tinha recebido a devida importância que merecia no marketing de serviços.

Como limitação do estudo, considerando que a seleção da amostra ocorreu pelo tipo bola de neve, reconhece-se que pode ter acontecido viés por estar pesquisando em um grupo que possui identificação e que pode não ser representativo do universo.

\section{REFERÊNCIAS}

ADDIS, M.; HOLBROOK, M. B. On the conceptual link between mass customization and experiencial consumption: an explosion of subjective. Journal of Consumer Behavior, v. 1, n. 1, p. 50-66, 2001.

BAGOZZI, R. P.; GOPINATH, M.; NYER, P. The role of emotions in marketing. Academy of Marketing Science Journal, v. 27, n. 2, p. 184- 206, 1999.

BAKER, J.; CAMERON, M. The effects of the service environment on affect and consumer perception of waiting time: an integrative review and research propositions. Academy of Marketing Science Journal, v. 24, n. 4, p. 338-349, 1996.

REMark - Revista Brasileira de Marketing, São Paulo, v. 8, n. 1, p 43-69, jan./jun. 2009. 
BAKER, J.; PARASURAMAN, A.; GREWAL, D. The influence of store environment on quality inferences and store image. Journal of the Academy of Marketing Science, Greenvale, v. 22, n. 4, p. 328-339, 1994.

BERRY, L. L.; CARBONE, L. P.; HAECKEL, S. H. Managing the total customer experience. MIT Sloan Management Review, Cambridge, v. 43, n. 3, p. 85-89, 2002.

BITNER, M. J. Evaluating service encounters: the effects of physical surroundings and employee responses. Journal of Marketing, New York, v. 54, p. 69-82, 1990.

BITNER, M. J. Servicescape: the impact of physical surroundings on customer and employees. Journal of Marketing, New York, v. 56, n. 2, p. 57-71, 1992.

CUNHA, L. O poderoso mercado gay. Revista ISTOÉ Dinheiro, São Paulo, n. 457, p. 66-69, jun. 2006.

DELOZIER, W. M.; RODRIGUE, J. Marketing to homosexual (gay) market: a profile and strategy implications. In: WARDLOW, D. L. (Org.). Gays, lesbians and consumer behavior: theory, practice and research issues in marketing. New York: Harrington Park Press, 1996. p. 203-211.

DONOVAN, R. J.; ROSSITER, J. R. Store atmosphere: an environmental psychology approach. Journal of Retailing, New York, v. 58, n. 1, 1982.

DUBE, L.; LE BEL, J.; SEARS, D. From customer value to engineering pleasurable experiences in real life and online. Cornell Hotel and Restaurant Administration Quarterly, v. 44, n. 5/6, p. 124-131, 2003.

FISCHER, A. Quem é o público GLS. Disponível em: <http://72.14.203.104/search?q=cache:rG4cF1nqXLkJ:www.mgm.org.br/revista/julho/capa.htm +\%22mercado+GLS\%22\&hl=pt-BR\&gl=br\&ct=clnk\&cd=11>. Acesso em: 02 maio 2006.

FUGATE, D. L. Evaluating the US male homosexual and lesbian population as a viable target market segment. Journal of Consumer Marketing, Chicago, v. 10, n. 4, p. 46-57, 1993.

GRESSLER, L. A. Introdução à pesquisa: projetos e relatórios. São Paulo: Loyola, 2004.

HASLOP, C.; HILL, H.; SCHIMIDT, R. A. The gay lifestyle- spaces for a subculture of consumption. Marketing Intelligence \& Planning, v. 16, n. 5, p. 318-326, 1998.

HIRSCHMAN, E. C.; HOLBROOK, M. B. Hedonic consumption: emerging concepts, methods and propositions. Journal of Marketing, New York, v. 46, p. 92-101, 1982.

REMark - Revista Brasileira de Marketing, São Paulo, v. 8, n. 1, p 43-69, jan./jun. 2009. 
HOFFMAN, K. D.; TURLEY, L. W. Atmospherics, service encounters and consumer decision making: an integrative perspective. Journal of Marketing Theory and Practice, v. 10, p. 3347, 2002.

HUGHES, H. L. Marketing gay tourism in Manchester: new market for urban tourism or destruction of "gay space"? Journal of Vacation Marketing, v. 9, n. 2, p. 152-163, 2002.

KATES, S. M. Making the ad perfectly queer: making "normality" to the gay men's community? Journal of Advertising, Atlanta, v. 28, n. 1, p. 25-37, 1999.

KATES, S. M. Twenty million new customers! Understanding gay men's consumer behavior. New York: Harrington Park, 1998.

KNUTSON, B. J.; BECK, J. A. Identifying the dimensions of the experience construct: development of the model. Journal of Quality Assurance in Hospitality \& Tourism, v. 4, n. 3/4, p. 23-35, 2003.

KOTLER, P. Atmospherics as a marketing tool. Journal of Retailing, New York, v. 49, p. 48-64, 1973.

KOTLER, P.; ARMSTRONG, G. Princípios de marketing. Rio de Janeiro: LTC, 1999.

LUKENBILL, G. Untold millions: secret truths about marketing to gay and lesbian consumers. New York: Harrington Park, 1999.

MEHRABIAN, A.; RUSSEL, J. A. An approach to environmental psychology. Cambridge: MIT Press, 1974.

MERRIAM, S. B. Qualitative research and case study applications in education. San Francisco: Jossey-Bass, 1998.

NEWMAN, P. J.; NELSON, M. R. Mainstream legitimization of homosexual men through valentine's day gift-giving and consumption ritual. In: WARDLOW, D. L. (Org.). Gays, lesbians and consumer behavior: theory, practice and research issues in marketing. New York: Harrington Park, 1996. p. 57-69.

NUNAN, A. Homossexualidade: do preconceito aos padrões de consumo. Rio de Janeiro: Caravansarai, 2003.

OLIVEIRA, L. A. Turismo para gays e lésbicas: uma viagem reflexiva. São Paulo: Rocca, 2002.

REMark - Revista Brasileira de Marketing, São Paulo, v. 8, n. 1, p 43-69, jan./jun. 2009. 
PATTON, M. Q. Qualitative research and evaluation methods. California: Sage, 2001.

PENÃZOLA, L. We're here, we're queer, and we're going shopping! A critical perspective on the accommodation of gays and lesbians in the U.S. marketplace. In: WARDLOW, D. L. (Org.). Gays, lesbians and consumer behavior: theory, practice and research issues in marketing. New York: Harrington Park, 1996. p. 9-41.

PEREIRA, B. N.; AYROSA, E. A. T.; OJIMA, S. Consumo entre gays: compreendendo a construção da identidade homossexual através do consumo. In: ENCONTRO DA ASSOCIAÇÃO NACIONAL DE PÓS-GRADUAÇÃO E PESQUISA EM ADMINISTRAÇÃO, 29., 2005, Brasília. Anais... Rio de Janeiro: ANPAD, 2005. 1 CD-ROM.

PORIA, Y. Assessing gay men and lesbian women's hotel experiences: an exploratory study of sexual orientation in the travel industry. Journal of Travel Research, v. 44, n. 3, p. 327-334, 2006.

PULLMAN, M. E.; GROSS, M. A. Welcome to your experience: where you can check out anytime you'd like, but you can never leave. Journal of Business and Management, v. 9, n. 3, 2003.

SALAZAR, V. S. Ambiente de serviços e satisfação do consumidor: um estudo em restaurantes na cidade de Recife. 2006. 109 f. Dissertação (Mestrado em Administração) - Curso de PósGraduação em Administração, Universidade Federal de Pernambuco, Recife, 2006.

SCHMITT, B. H. Marketing experimental. São Paulo: Nobel, 2002.

SCHMITT, B. H.; SIMONSON, A. A estética do marketing. São Paulo: Nobel, 2000.

TURLEY, L. W.; FUGATE, D. L. The multidimensional nature of service facilities: viewpoints and recommendations. The Journal of Services Marketing, v. 6, n. 3, p. 37-46, 1992.

TURLEY, L. W.; MILLIMAN, R. E. Atmospheric effects on shopping behavior: a review of the experimental evidence. Journal of Business Research, New York, v. 49, p. 193-211, 2000.

WAITT, G.; MARKWELL, K. Gay tourism: culture and context. New York: Haworth Hospitality, 2006.

WAKEFIELD, K. L.; BLODGETT, J. G. Customer responses to intangible and tangible factors. Psychology \& Marketing, v. 16, n. 1, 1999.

REMark - Revista Brasileira de Marketing, São Paulo, v. 8, n. 1, p 43-69, jan./jun. 2009. 
WARDLOW, D. L. Introduction. In: WARDLOW, D. L. (Org.). Gays, lesbians and consumer behavior: theory, practice and research issues in marketing. New York: Harrington Park, 1996. p. 1-8.

WIKSTRÖM, S. When products and service are not enough. ECR Journal, v. 4, n. 2, 2004.

ZANELLA, L. C.; CÂNDIDO, Í. Restaurante: técnicas e processos de administração e operação. Caxias do Sul: EDUCS, 2002

\author{
FACTORS OF THE HOTELS ENVIRONMENT AND THE EXPERIENCE OF \\ CONSUMPTION: A QUALITATIVE RESEARCH WITH HOMOSEXUALS OF RECIFE
}

\begin{abstract}
This study aims at describing the hotel environmental factors that most influence the consumption experience of the interviewed homosexuals. Aiming at finding out the perspectives of the masculine gender respondents who live in the city of Recife, it was developed a qualitative research in which the semi-structured method of interviewing was used. The results indicated that the lighting, cleaning and aroma (environmental conditions); the bed, the area of preference and functionality (space and functionality); the decoration (signs, symbols and artifacts), the breakfast and cable TV (extrinsic benefits), and the hotels employees (factor of the social environment of hotels) were the environmental factors of hotels that most influenced the consumption experience of the homosexuals interviewed. It was also verified the level of detail and the exigency of such public.
\end{abstract}

Keywords: Consumption Experience; Hotel; Service Environment.

REMark - Revista Brasileira de Marketing, São Paulo, v. 8, n. 1, p 43-69, jan./jun. 2009. 
Data do recebimento do artigo: 09/02/2009

Data do aceite de publicação: 13/04/2009

REMark - Revista Brasileira de Marketing, São Paulo, v. 8, n. 1, p 43-69, jan./jun. 2009. 